\title{
Methanol Intoxication in Patient due to the Chronic Usage of Alcohol and Cologne
}

\author{
Murat Tolga AVŞAR, Mehmet TOPTAŞ, Eren DEMIR, Çağatay METIN
}

Department of Anesthesiology and Reanimation, Haseki Training and Research Hospital, İstanbul, Turkey

\section{ABSTRACT}

Methyl alcohol is toxic liquid that is found in substances such as mercury and antifreeze. Methanol intoxication is severe disease and may cause death. Sixty years old man was admitted to our emergency clinic complaints of impaired consciousness. In his history he is chronic alcoholic and usage of cologne. He was transferred to intensive care unit and sedatisized and curarized due to the his glasgow coma scale being under eight. 40\% ethanol, folic acid, thiamine and 5\% dextrose were given with nazogastric tube. Sodium bicarbonate was given due to the acidosis. The patient was discharged with complaintsts of blindness after ninth day of his admission.

Keywords: Methyl alcohol, cologne, intoxication

\section{Introduction}

Methanol is a colorless and odorless substance that is in liquid state at room temperature (1). At present, it is produced as synthetic from the catalytic reduction of carbon monoxide (2). Poisoning by methanol, which is a type of alcohol that is obtained through the distillation of wood, can lead to serious mortality and morbidity. Methanol itself is not so toxic, but its metabolites are very toxic. It is metabolized to formaldehyde and then to formic acid by hydrogenase in alcohol. These metabolites are responsible for methanol intoxication that can cause metabolic acidosis, blindness, hemodynamic instability, and death (3). When it is orally taken, it is rapidly absorbed by the gastrointestinal system as ethyl alcohol (1).

Following the oral intake, it reaches high levels in the kidney, liver, and gastrointestinal system. It also exists in the vitreous humor and optic nerve at high levels (3). Visual impairments, headache, dizziness, and confusion typically occur in intoxications. In more severe intoxication cases, cerebral edema and associated coma and convulsion are observed (1). Our case was a patient having a history of chronic alcohol and cologne consumption and presenting with toxic signs associated with high amount of cologne intake. In this study, it was aimed to present this case by reviewing literature on treatment approaches to methanol intoxication.

\section{Case presentation}

A 60-year-old male patient was admitted to the emergency unit of our hospital due to impaired consciousness and progression in vision loss. When his medical history was investigated, it was learned that he had no known history of any disease, was a chronic alcoholic for 20 years, and was chronically drinking cologne for five years. His family stated that he had visual impairment for a long time, but he had not consulted any physician. Three hours before admission to the emergency unit, he had drunk a large amount of cologne and alcohol. Blood gas analysis revealed a $\mathrm{pH}$ value of 6.9, $\mathrm{pCO}_{2}$ of $24 \mathrm{mmHg}, \mathrm{pO}_{2}$ of $154 \mathrm{mmHg}, \mathrm{HCO}_{3}$ of $5.3 \mathrm{mmol} / \mathrm{L}$, base excess of $-25 \mathrm{mmol} / \mathrm{L}$, and anion gap of 30 . The patient was taken into the intensive care unit. After sedation and curarization, orotracheal intubation was performed on him. His vital findings were as follows: Blood pressure: $134 / 80 \mathrm{mmHg}$, peak heart rate: $88 / \mathrm{min}$, diuresis: active, and temperature: $36.2^{\circ} \mathrm{C}$. His pupils were dilated and no light reflex was observed in both eyes. The results of biochemical analysis were as 
follows: Hemoglobin: $16.9 \mathrm{gr} / \mathrm{dL}$, hematocrit $49.5 \%$, platelet count: $319 / \mathrm{mm}^{3}$, white blood cell count: $11.600 / \mathrm{mm}^{3}$, coagulation values: normal, aspartate transaminase: $119 \mathrm{u} / \mathrm{L}$, alanine transaminase: $41 \mathrm{u} / \mathrm{L}$, lactate dehydrogenase: $378 \mathrm{u} / \mathrm{L}$, gamma glutamyl transferase: $203 \mathrm{u} / \mathrm{L}$, sodium: $136 \mathrm{meq} / \mathrm{L}$, potassium: $7 \mathrm{mmol} / \mathrm{L}$, chlorine: $104 \mathrm{mmol} / \mathrm{L}$, and calcium: $9.33 \mathrm{mg} / \mathrm{dL}$. For the purpose of hydration, 5\% dextrose administration was begun. Vitamin B and folic acid were administered to the patient. Fomepizole was not administered because it was not available in our hospital. Five ampoules of sodium bicarbonate were administered by intravenous push. Infusion at the dose of $1 \mathrm{meq} / \mathrm{kg}$ was started as the patient had deep acidosis. Nasogastric catheter was inserted, through which $1.8 \mathrm{~mL} / \mathrm{kg} 40 \%$ ethanol loading dose was administered. The maintenance dose was administered at the dose of $0.46 \mathrm{~mL} / \mathrm{kg} /$ hour. Ethanol administration was stopped when $\mathrm{pH}$ value was found to be $>7.25$ in the blood gas. With active diuresis and infusions of bicarbonate and ethanol, $\mathrm{pH}$ was improved in the arterial blood gas. Blood methanol level could not be evaluated because it was not analyzed in our hospital. Because his consciousness was recovered at the 30th hour following the admission to the intensive care unit and he had adequate spontaneous respiration, he was extubated and followed with an $\mathrm{O}_{2}$ mask. On the ninth day of admission to the intensive care unit, he was discharged from the hospital with full visual loss in both eyes.

\section{Discussion}

Methanol is a substance that comprises very toxic metabolites and affects the central system. Its metabolites are responsible for metabolic acidosis, blindness, hemodynamic instability, and methanol intoxication that can cause death (3). In Turkey, while 124 cases of methanol toxicity were reported by Turla et al. between 1992 and 1997, 205 cases were reported in the study by İnanıc1 et al. between 1994 and 1998 (4-6). In chronic alcoholics, the intake of methanol instead of ethanol is a significant issue $(7,8)$. Patients are mostly between the ages of 30 and 40 years and most of them (80\%-90\%) are male (5).

In Turkey, $42.5 \%$ of methanol intoxication-induced deaths reportedly result from alcoholic drinks and 19.2\% from drinking cologne (9). The findings of methanol intoxication are generally restricted with the findings of the central nervous system, eyes, and gastrointestinal system. In addition to visual impairment, headache, nausea, vomiting, abdominal pain, and dyspnea can occur (1). In severe cases, extrapyramidal system findings such as tremor, rigidity, and bradykinesia are observed as in Parkinson's disease (10).

The general approach to methanol intoxication includes gastric irrigation, the administration of ethanol, fomepizole, folate, and thiamine, and hemodialysis (3). Gastric irrigation should be performed in patients who are admitted within one hour after intake. It was not performed in our patient because he was admitted approximately three hours after in- take. Activated charcoal should not be used in such cases since methanol does not bind well with activated charcoal. Ethanol is used in the traditional first-line treatment of methanol intoxication and it can be administered orally, intravenously, or through a nasogastric tube.

In the present case, ethanol was administered through a nasogastric tube. Fomepizole is a competitive inhibitor of alcohol dehydrogenase and it inhibits the conversion of methanol to formic acid, which is its major metabolite.

Dialysis should be performed in a patient with methanol intoxication in the presence of visual symptoms, central nervous system dysfunction findings, methanol level above $25 \mathrm{mg} / \mathrm{dL}$, severe metabolic acidosis, or history of intake over $30 \mathrm{~mL}$. In this case, deep acidosis was dissolved by giving ethanol and administering sodium bicarbonate. Dialysis was not initiated because the onset of visual loss was not acute, methanol level could not be evaluated, and diuresis was active.

\section{Conclusion}

Methanol intoxication can be fatal unless it is properly treated. It should be considered in patients with mental fog, nausea, vomiting, visual loss, increased anion gap, and metabolic acidosis and its treatment should be begun as soon as possible. Blood methanol level should be evaluated and the treatment of thiamin, folic acid, 5\% dextrose, and fomepizole should be initiated. In the presence of refractory acidosis, sodium bicarbonate therapy and dialysis should be administered.

Informed Consent: Due to the retrospective nature of this study, informed consent was waived.

Peer-review: Externally peer-reviewed.

Author Contributions: Concept - M.T.A.; Design - M.T.A., M.T.; Supervision - M.T.A.; Resources - M.T.A.; Data Collection and/or Processing - M.T.A., E.D., Ç.M., M.T.; Analysis and/or Interpretation -M.T.A., M.T.; Literature Search - E.D., C.M.; Writing Manuscript - M.T.A., M.T.; Critical Review - M.T.

Conflict of Interest: No conflict of interest was declared by the authors.

Financial Disclosure: The authors declared that this study has received no financial support.

\section{References}

1. Barceloux GD, Bond GR, Krenzelok EP, Cooper H, Vale JA. American Academy of Clinical Toxicology Practice Guidelines on the Treatment of Methanol Poisoning. Clinical Toxicology, 2002; 40: 415-46.

2. IPCS, Healthy and Safety Guide No. 105. Methanol; World Healthy Organization: Geneva, 1997; 105.

3. Berk WA, Henderson WV. Alcohols. In Tintinalli JE, Kelen GD. 1. Stapczynski JS, editor. Emergency Medicine. A Comprehensive.Study Guide. 5th ed. New York: McGraw Hill; 2000. p.1103-1109.

4. Blanco M, Casado R, Vazquez F, Pumar JM. CT and MR imaging findings in methanol intoxication. AJNR Am J Neuroradiol 2006; 27: 452-4. 
5. Yaycı N, İnanıcı MA. Metil Alkol (Metanol) Zehirlenmesi.Türkiye Klinikleri J Foren Med 2005; 2: 101-108.

6. Turla A,Yaycı N, Koç S. Ölümle sonuçlanan metil alkol zehirlenmeleri. Adli Tip Dergisi 2001; 15: 37-40.

7. Naraqi S, Dethlefs RF, Slobodniuk RA, Sairere JS. An outbreak of acute methyl alcohol intoxication. Aust N Z J Med 1979; 9: 65-68. [CrossRef]
8. Yayci N, Ağritmiş H, Turla A, Koç S. Fatalities due to methyl alcohol intoxication in Turkey: an 8 year study. J Forensic Sci 2003; 131: 36-41. [CrossRef]

9. Elmas İ, Tüzün B, İmrağ C, Korkut M. Evaluation of deaths due to methyl alcohol intoxication with respect to forensic medicine 1996; 59: 64-69.

10. Oliveras Ley,C., Gali G. Parkinsonien Syndrome after Methanol Intoxication. Eur Neurol1983; 22: 405-409. [CrossRef] 